DOI: $10.17805 / z p u .2015 .2 .12$

\title{
Тренды религиозного возрождения в регионах России (на примере сибирских татар-мусульман)
}

Н. Г. ХАЙРУЛЛИНА

(ТЮМЕНСКИЙ ГОСУДАРСТВЕННЫЙ НЕФТЕГАЗОВЫЙ УНИВЕРСИТЕТ)

В статье анализируются особенности процессов религиозного возрождения в российских регионах у разных этносов на примере сибирских татар Тюменской области.

Материалом для анализа стали результаты этносоциологического исследования состояния современной конфессиональной ситуации в Тюменской области в 2014 г. Исследование ведется в рамках работы над проектом «Татары в регионах Российской Федерации: религиозное возрождение и проблемы идентичности. Этносоциологическое исследование современной ситуации» Академии наук Республики Татарстан и поддерживается Государственной программой «Сохранение национальной идентичности татарского на- 
рода (2014-2016 гг.)». Респондентами выступили эксперты, духовенство, верующие представители национальной интеллигенции (15 чел.), с которыми были проведены глубинные интервью.

В числе задач исследования - выявление специфики религиозности татар, характеристика религиозных практик и каналов получения религиозных знаний, определение трендов изменения религиозной идентичности и ее связи с другими формами идентичности, выявление роли ислама в сохранении этнической идентичности.

Ответы респондентов выявляют позитивную оценку роли религии в жизни татарского населения. По мнению экспертов, в современном мире религия выполняет в основном духовно-нравственные функции. Большинство верующих считают, что религия придает смысл жизни, помогает перенести трудности, приносит успокоение, способствует сохранению национальной культуры и традиций, взаимопониманию верующих разных религий, нравственному состоянию общества, удерживает от аморальных поступков.

Социально-демографические характеристики религиозных и нерелигиозных представителей татарского населения в настоящее время размыты. Сегодня трудно проследить четкую зависимость уровня религиозности от возраста, социального положения, места жительства, образования, семейного положения, уровня доходов респондентов. Это было подтверждено и в ходе глубинных интервью при проведении этносоциологического исследования летом 2014 г.

Мониторинговые исследования позволили выявить динамику мнений респондентов о том, существует ли опасность для представителей татарского населения утратить национальную самобытность. За период с 2001 по 2010 г. с 11,8 до 17,3\% увеличилось число респондентов, не опасающихся утраты татарами национальной самобытности.

Полученные данные будут учтены при формировании государственной и региональной национальной политики, способствовать активизации этнического самосознания, гармонизации взаимоотношений с представителями других национальностей и религий.

Ключевые слова: сибирские татары, Тюменская область, ислам, религиозное возрождение, татары, этническая идентификация, религиозная идентичность.

\section{ВВЕАЕНИЕ}

$\mathrm{B}$ декабре 2012 г. на V Съезде Всемирного конгресса татар была одобрена Концепция сохранения этнической идентичности татарского народа, которая нацелена на обеспечение реализации этнокультурных потребностей и интересов татарского народа, его устойчивого развития и роста общего благосостояния, укрепление единства татарской этнокультурной общности, обеспечение межэтнического мира и согласия путем создания условий для сохранения культуры и языка татарского народа, согласование общегосударственных интересов и интересов татарского населения, сохранение единства и целостности Российской Федерации. Спустя почти год Кабинет министров Республики Татарстан утвердил государственную программу «Сохранение национальной идентичности татарского народа (2014-2016 гг.)», разработанную исполкомом Всемирного конгресса татар и Министерством культуры Республики Татарстан.

Программа основывается на Стратегии государственной национальной политики Российской Федерации на период до 2025 г., утвержденной Указом Президента Российской Федерации от 19 декабря 2012 г. № 1666, а также Концепции государственной национальной политики в Республике Татарстан и направлена на создание условий Аля сохранения и развития национальной идентичности татар в самой республике и за ее пределами. Программа предусматривала проведение социологических исследований состояния современной конфессиональной ситуации в регионах проживания татар. Руководитель проекта - Р. Н. Мусина (Татары и ислам в регионах Российской Федерации ..., 2014). 
В постсоветский период в российском обществе актуализировались архаизационные процессы (Иамажаа, 2011; Ааргын-оол, 2003, 2005; Аорошин, 2010), в том числе с особой остротой встали религиозные проблемы в каждом из регионов страны, в частности в Тюменской области (Иамажаа, Хайруллина, 2015; Хайруллина, 2012; Артюхов, Хайруллина, 2012; Хайруллина, Койше, 2013). Обращение к религии проявляется не только на уровне массового сознания, эти вопросы обсуждаются учеными, политиками, представителями властных структур.

Среди российских мусульман татары - самый многочисленный мусульманский этнос, насчитывающий, по данным Всероссийской переписи населения 2010 г., более 5,3 млн чел. Они, несмотря на быстрый естественный прирост северокавказских мусульманских народов, по-прежнему доминируют в составе мусульманской общности страны, составляя 38,4\% ее численности (Гаврилов, Шевченко, 2012: 72). Татары широко расселены по многим российским регионам. Основная часть татар РФ проживает в республиках и областях Поволжья и Приуралья, значительная доля представителей татарского этноса живет в городах и районах Тюменской области. В Западной Сибири татары с начала XX в. называются «сибирскими татарами» (самоназвание татар - «себер татар», «себер татарлар») (Татары Тюменской области ..., 2011; Сибирские татары ... , 2014). Наибольшее число представителей татарского населения проживают в Тюменском (12 734 чел.), Вагайском (10 235 чел.), Тобольском (8492 чел.) и Ярковском (8265 чел.) районах Тюменской области.

\section{МЕТОАИКА ИССАЕАОВАНИЯ}

Иетом 2014 г. нами было проведено этносоциологическое исследование с целью изучения конфессиональной ситуации в регионах компактного проживания татар Тюменской области. Аля этого с экспертами (представителями властных структур и национальной интеллигенции), с представителями мусульманского духовенства и верующими (всего 15 чел.) были проведены глубинные интервью. В интервью приняли участие 5 женщин и 10 мужчин: в категории «экспертов» - трое мужчин и две женщины; «представители духовенства» - четверо мужчин и одна женщина, «верующие»трое мужчин и две женщины. Возрастные характеристики опрошенных: эксперты от 35 до 58 лет, представители духовенства - от 38 до 70 лет, верующие - от 30 до 75 лет. Гайд-интервью (руководство интервьюера с перечнем открытых вопросов) для экспертов содержало 88 вопросов, для представителей мусульманского духовенства 92 вопроса, верующих - 80 вопросов. Участники интервью выступали анонимно.

Среди основных задач исследования были выделены следующие:

1) выявить специфику религиозности татар;

2) охарактеризовать религиозные практики и каналы получения религиозных знаний;

3) рассмотреть тренды изменения религиозной идентичности и ее связи с другими формами идентичности;

4) изучить роль ислама в сохранении этнической идентичности.

Аля анализа результатов исследования использовались данные органов статистики, этносоциологических исследований, проведенных ранее в Тюменской области (Хайруллина, Салихова, 2004; Хайруллина, 2010, 2011). В ходе полевой работы производилась также фотофиксация сюжетов по теме исследования (мечетей, проведения религиозных обядов и пр.).

Гайд-интервью включало ряд блоков вопросов по темам: «Возрождение религии, проявления религиозности», «Религия и религиозность» и «Религия и этничность». 


\section{ВОЗРОЖАЕНИЕ РЕАИГИИ, ПРОЯВАЕНИЯ РЕАИГИОЗНОСТИ}

В беседе с экспертами мы подчеркнули: «...в последние 20 лет заметно усилился интерес людей к религии, приобщение к тем или иным конфессиям. Это проявляется и в посещении храмов, и в выполнении различных религиозных предписаний. Часто говорят о религиозном возрождении у нас в стране в целом и об исламском возрождении среди татар». В связи с этим был сформулирован вопрос: «Как вы считаете, это действительно так? В чем это проявляется в вашем регионе?» На данный вопрос все эксперты ответили утвердительно. При этом они обратили внимание, что к религии сегодня приобщаются представители не только старшего и среднего поколения, но и младшего поколения и даже школьного возраста. По их мнению, наблюдается преемственность поколений через приобщение к исламу, проведение праздников, соблюдение обычаев и обрядов, приучение к исламской духовности, исламским традициям (Хайруллина, 2014).

Один из респондентов - представителей церкви сказал: «...молодое поколение приобщается к религии в большей степени; в мечетях сейчас много молодежи и представителей старшего поколения. Представителей среднего поколения очень мало, они попали под влияние комсомола, это потерянное поколение. У молодежи интерес к религии не испорчен» (имам, 35 лет). Аругой респондент - представитель республиканской власти, считает: «...интерес к исламу в сегодняшней ситуации будет только усиливаться, поэтому в регионе больше внимания уделяется этим вопросам. В Тюменской области восстанавливаются объекты религиозного назначения (мечети, храмы), решаются проблемы образования (обучение студентов). “Свежая кровь”, обучившаяся в Татарстане и Уфе, - это когорта богословов, которая будет на новом уровне в регионе приобщать татарское население к религии» (муж., госслужащий, 35 лет).

Следует отметить, что такая оценка присутствует и в ответах представителей духовенства, принявших участие в интервью. Например, один респондент сказал: «Последние десять лет особенно стало заметно религиозное возрождение. Причем заметно чаще среди представителей молодого поколения. Молодые люди читают намаз, женятся по мусульманским традициям, опускают бороды, заводят две и более жен. Женщины молодые носят традиционную для мусульманок одежду, платки, чаще воспитывают детей дома, чем работают» (имам, 49 лет).

На вопрос о том, по каким признакам эксперты судят о процессе религиозного возрождения («Сегодня много говорят о религиозном возрождении у нас в стране. В вашем окружении это заметно? Как вы считаете, с чем это связано?»), верующие Тюменской области, принявшие участие в интервью, дали конкретные примеры из жизни своей или своих родственников: «Молодежь старается при вступлении в брак сделать никах, дают детям мусульманские имена, заводят не одного, а троих и более детей, обращают внимание на традиции своего народа. Мои родственники держат пост, читают намаз, проводят поминальные мероприятия, помогают нуждающимся» (муж., служащий, 47 лет); «Сын с 16 лет встал на намаз, женился на татарской девушке, она теперь тоже читает намаз. Аочери и зять с сыном держат пост, проводят наши мероприятия, приносят в жертву баранов в Корбан, детям дают мусульманские имена. Не пьют спиртное, не курят. Члены моей семьи ведут здоровый образ жизни» (муж., предприниматель, 57 лет); «Мой двою-родный брат, глядя на меня, встал на намаз, женился на татарке, у нас совместный бизнес. Все мои друзья также исповедуют ислам. У некоторых две и три 
жены, они обеспечивают их одинаково. Ходим все на пятничный намаз» (муж., директор ЧП, 29 лет).

\section{РЕАИГИЯ И РЕАИГИОЗНОСТЬ}

Анализируя ответы әкспертов о том, что дает религия сегодня людям, можно отметить позитивную оценку роли религии в жизни татарского населения. Это прослеживается в ответах всех экспертов. «Религия дает людям душевную умиротворенность, и через Коран происходит принятие духовной культуры, правил морального поведения, мотивации окружающих нас людей» (муж., госслужащий, 58 лет). «При социализме у нас были идеалы, мы строили коммунизм, была определенная идеология. У людей воспитывались чувства равенства, братства. Когда на смену этим принципам пришли другие (наживы, стремления больше заработать), религия не позволяет нам перейти на «волчьи законы» и позволит сохранить добро. Религия дает возможность приобщиться к истории и учит терпимости, помогает жить в равенстве» (муж., общественный деятель, 56 лет).

По мнению экспертов, в современном мире религия выполняет в основном духовно-нравственные функции, например «объединяет людей, которые имеют сходство в своих взглядах на веру», «воспитывает духовность, учит делать добро близким и окружающим, становиться лучше, расти нравственно». «В современном мире религии придается большее значение, чем в бывшем СССР, когда на протяжении нескольких десятилетий она не признавалась. Но СССР распался. А воспитание было там построено на моральном кодексе строителя коммунизма (он не противоречит заповедям Корана или Библии). Считаю, что главная функция религии сегодня - гармонизация межнациональных и межконфессиональных отношений» (муж., госслужащий, 58 лет).

Во время интервью верующим был задан вопрос, что дает религия сегодня людям. Большинство верующих ответили, что религия придает смысл жизни, приносит успокоение, помогает перенести трудности, способствует сохранению национальной культуры и традиций, взаимопониманию верующих разных религий, нравственному состоянию общества, удерживает от аморальных поступков. «Религия является нравственным контролером совести человека» (жен., домохозяйка, 47 лет).

\section{РЕАИГИЯ И ЭТНИЧНОСТЬ}

Аля современной жизни России характерными становятся рост национального самосознания и готовность защищать ценности традиционной культуры и особые права на ее сохранение в условиях нарастания интеграции у представителей разных народов, в том числе и у исследуемых нами народов - сибирских татар. Подъем национализма, тесно связанный с ростом этничности, зафиксирован в исследованиях автора, проведенных в 2001-2010 гг. (Хайруллина, 2013). Индикатором сказанного могут служить ответы татар Тюменской области на вопрос о степени удовлетворенности своей национальной принадлежностью (табл. 1, с. 122).

На вопрос о том, к какой национальности себя относят, чуть более четверти опрошенных $(28,2 \%)$ назвали себя татарином (татаркой). Остальные участники анкетного опроса, таких по данным исследования 70,2\%, конкретизировали свои ответы: две трети представителей татарского населения (62,4\%) назвали себя сибирским татарином (татаркой), 7,8\% - казанским татарином (татаркой). 
Таблииа 1

АИНАМИКА ОТВЕТОВ РЕСПОНАЕНТОВ НА ВОПРОС О СТЕПЕНИ УАОВАЕТВОРЕННОСТИ СВОЕЙ НАЦИОНААЬНОЙ ПРИНАА ЕЖНОСТЬЮ, В \% К ОБЩЕМУ ЧИСАУ ОТВЕТИВШИХ

Table 1

DYNAMICS OF RESPONDENTS' ANSWERS TO THE QUESTION ON HOW SATISFIED

THEY ARE WITH THEIR ETHNIC IDENTITY (\% OF THE TOTAL NUMBER OF RESPONSES)

\begin{tabular}{|l|r|r|}
\hline \multicolumn{1}{|c|}{ Степень удовлетворенности } & \multicolumn{2}{|c|}{ Год } \\
\cline { 2 - 3 } & 2001 & 2010 \\
\hline Удовлетворен & 77,7 & 89,3 \\
Не удовлетворен & 1,7 & 2,3 \\
Не придаю значения национальной принадлежности & 13,5 & 6,0 \\
Затрудняюсь ответить & 7,1 & 2,4 \\
\hline
\end{tabular}

Представим мировоззренческие позиции респондентов по отношению к религии в целом и в зависимости от национальной принадлежности (табл. 2), в частности полученные в ходе опроса в 2010 г.

Таблица 2

МИРОВОЗЗРЕНЧЕСКИЕ ПОЗИЦИИ РЕСПОНАЕНТОВ ПО ОТНОШЕНИЮ К РЕАИГИИ В ЗАВИСИМОСТИ ОТ НАЦИОНАЦЬНОСТИ, В \% К ОБЩЕМУ ЧИС УУ ОТВЕТИВШИХ

Table 2

RESPONDENTS' VIEW OF RELIGION WITH RESPECT TO THEIR ETHNICITY (\% OF THE TOTAL NUMBER OF RESPONSES)

\begin{tabular}{|c|c|c|c|c|}
\hline \multirow[b]{2}{*}{$\begin{array}{c}\text { Вариант } \\
\text { ответа }\end{array}$} & \multirow[b]{2}{*}{$\begin{array}{c}\text { Все } \\
\text { респонденть }\end{array}$} & \multicolumn{3}{|c|}{ Начиональность } \\
\hline & & $\begin{array}{c}\text { татарин } \\
\text { (татарка) }\end{array}$ & $\begin{array}{c}\text { сибирский } \\
\text { татарин } \\
\text { (татарка) }\end{array}$ & $\begin{array}{c}\text { казанский } \\
\text { татарин } \\
\text { (татарка) }\end{array}$ \\
\hline А $a$, я верующий & 61,0 & 62,0 & 60,0 & 57,1 \\
\hline Нет, я неверующий & 5,8 & 7,0 & 5,9 & 8,9 \\
\hline Ищу дорогу к богу & 12,8 & 9,5 & 14,3 & 17,9 \\
\hline Затрудняюсь ответить & 20,4 & 21,5 & 19,8 & 16,1 \\
\hline
\end{tabular}

Социально-демографические характеристики религиозных и нерелигиозных представителей татарского населения в настоящее время размыты. Сегодня трудно проследить четкую зависимость уровня религиозности от возраста, социального положения, места жительства, образования, семейного положения, уровня дохода респондентов. Это было подтверждено и в ходе глубинных интервью при проведении этносоциологического исследования летом 2014 г.

Рассмотрим динамику ответов на вопрос, соблюдают ли респонденты обычаи своего народа, полученную в ходе мониторинговых исследований в течение 2001-2010 гг. (табл. 3). Как видно из данных, представленных в указанной таблице, ситуация за десять лет изменилась коренным образом. В 4,5 раза увеличилось число представителей татарского населения, полностью соблюдающих обычаи своего народа. 


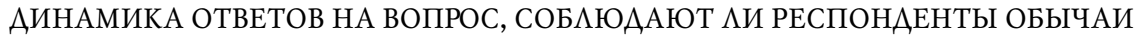

Таблича 3

СВОЕГО НАРОАА, В \% К ОБЩЕМУ ЧИСАУ ОТВЕТИВШИХ

DYNAMICS OF RESPONDENTS' ANSWERS TO THE QUESTION WHETHER

Table 3

THEY KEEP THE CUSTOMS OF THEIR PEOPLE

(\% OF THE TOTAL NUMBER OF RESPONSES)

\begin{tabular}{|l|r|r|}
\hline \multirow{2}{*}{ Объчаи соблюдаю } & \multicolumn{2}{|c|}{ Год } \\
\cline { 2 - 3 } & 2001 & 2010 \\
\hline Полностью & 6,1 & 27,2 \\
Частично & 65,0 & 64,6 \\
Не соблюдаю & 24,2 & 5,1 \\
Не знаю обычаев & 4,7 & 2,1 \\
Затрудняюсь ответить & - & 1,0 \\
\hline
\end{tabular}

Респондентам, положительно ответившим в 2010 г. на вопрос, соблюдают ли они обычаи своего народа, было предложено указать, какие именно обычаи они соблюдают. Представим ответы респондентов в порядке убывания значимости: «раздаю саадака» (милостыню) - 84,7\%; «провожу аш, хатым» (угощение, чтение Корана) $71,1 \%$; «провожу никах» - 64,2\%; «совершаю похоронный обряд» $-56,2 \%$; «исем кушу» (наречение имамом имени новорожденному) - 46,2\%; «посещаю мечеть» $34,8 \%$; «совершаю суннэт» (обрезание) - 30,5\%; «делаю жертвоприношение» $27,6 \%$; «вношу пожертвования на строительство мечетей, культовых сооружений» $20,4 \%$; «стараюсь употреблять в пищу только продукты халяль» - 17,8\%; «совершаю паломничество (хадж)»-1,6\%.

Индикатором того, что интерес к обычаям своего народа у представителей татарского населения не снижается, могут служить ответы представителей духовенства на вопрос: «Проводите ли вы некоторые религиозные обряды, такие как никах, исем кушу, в мечетях или же только в домашних условиях?», полученные в 2014 г. Bсе опрошенные ответили утвердительно на поставленный вопрос с разными комментариями: «Аа, провожу и в мечети, и дома» (имам, 49 лет); «Провожу и в мечети, и дома. Поминки не провожу, это местное нововведение» (имам, 35 лет); «Я женщина, мне по законам шариата не дозволено проводить религиозные обряды ни в мечети, ни дома, но имамы постоянно проводят в нашей мечети никах, исем кушу, заупокойную молитву и другие религиозные обряды» (настоятельница Ембаевской мечети, 56 лет).

Мониторинговые исследования позволили выявить динамику мнений респондентов о том, существует ли опасность для представителей татарского населения утратить национальную самобытность («Существует ли опасность для татар утратить свою национальную самобытность?») (табл. 4, с. 124) (Хайруллина, 2014: 277-307).

Из данных, представленных в табл. 4, видно, что за период с 2001 по 2010 г. с 11,8 до 17,3\% увеличилось число респондентов, не опасающихся утраты татарами национальной самобытности. Исходя из ответов представителей духовенства на вопрос: «А что сегодня ислам как духовная традиция дает татарскому народу в целом?», полученных в 2014 г. в ходе этносоциологического исследования, можно согласиться 


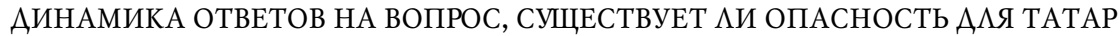

Таблииа 4

УТРАТИТЬ СВОЮ НАЦИОНААЬНУЮ САМОБЫТНОСТЬ,

В \% К ОБЩЕМУ ЧИСАУ ОТВЕТИВШИХ

Table 4

DYNAMICS OF ANSWERS TO THE QUESTION WHETHER THE DANGER

OF LOSING ETHNIC IDENTITY IS REAL FOR TATARS

(\% OF THE TOTAL NUMBER OF RESPONSES)

\begin{tabular}{|l|r|r|}
\hline \multirow{2}{*}{ Oпасность } & \multicolumn{2}{|c|}{ Год } \\
\cline { 2 - 3 } & 2001 & 2010 \\
\hline Существует & 37,7 & 39,9 \\
Существует, но ее не стоит преувеличивать & 28,6 & 24,3 \\
Нет & 11,8 & 17,3 \\
Никогда об этом не задумывался & 19,2 & 10,9 \\
Затрудняюсь ответить & 2,7 & 7,6 \\
\hline
\end{tabular}

с такой оценкой. Приведем некоторые ответы: «Сегодня ислам как духовная традиция сохраняет татарский народ. Ислам - универсальная религия, сохраняет каждый народ в красоте. Ислам идентифицирует нас и позволяет сохранить традиции, язык, культуру, кухню и др.» (имам, 35 лет); «Сегодня ислам как духовная традиция дает татарскому народу возможность соблюдать свои обычаи, традиции» (настоятельница мечети, 56 лет); «Религия позволяет вернуться к истокам, познать свою культуру, а через культуру познать обычаи, обряды, традиции, ритуалы. В Коране регламентирована наша жизнь» (имам, 49 лет).

Этническое самосознание, актуализированное в деятельности его конкретных носителей, быстро реагирует на меняющиеся условия социальной действительности. Если в повседневной жизни оно ярко проявляется лишь в организованных мероприятиях, то в период общественных преобразований носит массовую форму, приобретая иногда наступательный характер, выражающийся в противостоянии и конфликтах между этносами. В период экономических и социальных перемен наблюдаются нарушение принципа социальной справедливости, ущемление прав и свобод этнических меньшинств, разногласия в распределении привилегий и льгот, невнимание органов власти различных уровней к потребностям и игнорирование интересов какого-либо этноса. Вероятен и другой сценарий развития, когда представители этноса объединяются, привлекая внимание других к необходимости возрождения обычаев, традиций, обрядов своего народа (Хайруллина, 2010). Не случайно на вопрос, планируют ли респонденты в ближайшее время начать изучать, соблюдать национальные традиции и обычаи, почти каждый второй представитель татарской национальности $(46,9 \%)$ в 2010 г. ответил положительно. Противоположное мнение («нет») в шесть раз меньшего числа участников анкетного опроса $(6,9 \%)$. Вызывает тревогу, что более трети опрошенных $(38,0 \%)$ никогда об этом не задумывались, а почти каждый десятый $(8,2 \%)$ не смог ответить на поставленный вопрос. Чаще позитивное мнение высказывают женщины, а вот мужчины не задумываются над вопросом, стоит ли им начать в ближайшее время изучать, соблюдать национальные традиции и обычаи татарского народа. 


\section{ЗАКАЮЧЕНИЕ}

Таким образом, как показали проведенные нами исследования, в этноконфессиональной организации татар наблюдается стремительный рост и актуализация этнического и конфессионального самосознания, рост религиозности, усиление, особенно среди молодежи, «новой» мусульманской идентичности, нивелирующей зачастую этнокультурную специфику татар. Следует отметить существенную роль ислама в формировании толерантности к иным взглядам и убеждениям, этническим различиям, которые становятся обычной практикой социокультурной жизни региона. Аля мусульман Тюменской области созданы все условия для соблюдения религиозных традиций, обычаев, обрядов, изучения и пропаганды своей религии, гармонизации взаимоотношений с представителями других религий.

Проведенная работа позволяет наметить важные направления дальнейших исследований: выявление социальной базы религиозного ренессанса и специфики религиозности татар; характеристика религиозных практик и каналов получения религиозных знаний; рассмотрение трендов изменения религиозной идентичности и ее связи с другими формами идентичности; изучение роли ислама в сохранении этнической идентичности и этнокудьтурных ценностных ориентаций и установок; определение характера этноконфессионального взаимодействия в регионах и влияющих на него факторов, в том числе факторов интеграции/дезинтеграции татар-мусульман; выявление функций религиозных институтов (духовных управлений, мечетей) и мусульманского духовенства в современном обществе.

\section{СПИСОК АИТЕРАТУРЫ}

Артюхов, А. В., Хайруллина, Н. Г. (2012) Тенденции этнокультурной ситуации в Северном регионе // Знание. Понимание. Умение. № 3. С. 106-109.

Гаврилов, Ю. А., Шевченко, А. Г. (2012) О некоторых тенденциях изменения этнорелигиозной структуры населения России // Вестник Института социологии. № 4. С. 61-78.

Ааргын-оол, Ч. К. (2003) Культура как основа социального развития регионов России (на примере Тувы) // Гуманитарные науки в Сибири. № 3. С. 40-43.

Ааргын-оол, Ч. К. (2005) Региональный аспект социальных процессов в современной России // Социально-гуманитарные знания. № 1. С. 338-346.

Аорошин, Б. А. (2010) Основные архетипы социальной элиты в мифологических представлениях народов Поволжья // Вестник Поволжской академии государственной службы. № 2 (23). C. 209-217.

Аамажаа, Ч. К. (2011) Архаизация общества в период социальных трансформаций // Знание. Понимание. Умение. № 3. С. 35-42.

Аамажаа, Ч. К., Хайруллина, Н. Г. (2015) Архаизация и неотрадиционализм в регионах Уральского федерального округа // Знание. Понимание. Умение. № 1. С. 29-38.

Сибирские татары (2014) : библиогр. указ. : (XVIII в. - 2013 г.) / сост.: А. Х. Сайфуллина (сост.-ред.), Г. Н. Ахметова, Р. М. Насибуллин. Тюмень : Молот. 449 с.

Татары и ислам в регионах Российской Федерации: религиозное возрождение и этничность (2014) / рук. проекта и отв. ред. Р. Н. Мусина. Казань : Институт истории им. Ш. Марджани АН РТ ; Артифакт. 348 с.

Татары Тюменской области: история и современность (2011) / под ред. Р. Х. Насырова, Н. Г. Хайруллиной, В. С. Ташкаловой, 3. А. Тычинских. Тюмень : Вектор Бук. 310 с.

Хайруллина, Н. Г. (2010) Татары Тюменской области: динамика социокультурной ситуации. Тюмень : Изд-во ТюмГНГУ. 208 с.

Хайруллина, Н. Г. (2011) Социологический аспект явления этнической идентификации татар Тюменской области // Вестник Орловского государственного университета. Серия: Новые гуманитарные исследования. № 5 (19). С. 69-72. 
Хайруллина, Н. Г. (2012) Коренные народы Тюменской области: взгляд социолога. Тюмень : Изд-во ТюмГНГУ. 476 с.

Хайруллина, Н. Г. (2013) Межэтнические отношения в полиэтничном российском регионе: социологическое измерение // Вестник КГТУ им. А. Н. Туполева. № 1. С. 182-184.

Хайруллина, Н. Г. (2014) Процесс религиозного возрождения и проблемы этнической идентичности у татар Тюменской области // Татары и ислам в регионах Российской Федерации: религиозное возрождение и этничность / рук. проекта и отв. ред. Р. Н. Мусина. Казань : Институт истории им. Ш. Марджани АН РТ ; Артифакт. 348 с. С. 277-307.

Хайруллина, Н. Г., Койше, К. К. (2013) Этническая идентификация татар Тюменской области // Знание. Понимание. Умение. № 1. С. 116-120.

Хайруллина, Н. Г., Салихова, А. Р. (2004) Аинамика социокультурной ситуации на юге Тюменской области. Тюмень : Изд-во ТюмГНГУ. 128 с.

Aата поступления: 12.02 .2015 2.

\section{TRENDS OF RELIGIOUS REVIVAL IN RUSSIA'S REGIONS \\ (THE CASE OF MUSLIM SIBERIAN TATARS) \\ N. G. KHAIRULLINA \\ (TYUMEN StATE OIL AND GAS UNIVERSITY)}

The paper analyzes some features of religious revival in various ethnic groups within Russia's regions. The case in point here are Siberian Tatars living in Tyumen oblast.

Our study came as the outcome of an ethnosociological survey of the current religious situation in Tyumen oblast, conducted in 2014 as part of the project "Tatars in the Russian regions: Religious Revival and Identity Issues". The project is done under the aegis of the Academy of Sciences of the Republic of Tatarstan and supported by the State Program "Preservation of Tatars' National Identity" (2014-2016). The body of respondents comprised experts, clergymen, believers among the national intelligentsia (15 people all in all), who gave us in-depth interviews.

Among the objectives of our study were identifying the specifics of Tatar religiosity, of their religious practices and channels of obtaining religious knowledge, determining the directions of change in this religious identity and its relationship with other identity forms, and defining the role of Islam in the preservation of ethnic identity.

The respondents' answers reveal a positive assessment of the role of religion in the life of Tatars. According to the experts, in the modern world religion has primarily spiritual and moral functions. Most believers think that religion gives meaning to life; contributes to the moral state of society, keeps from immoral acts; brings the feelings of peace and comfort, helps to weather the difficulties of life; contributes to the preservation of national culture and traditions; and finally, promotes understanding of believers in different religions.

Socio-demographic differences between religious and non-religious Tatar population are quite blurred. It is difficult to clearly link the level of religiosity with respondents' age, social status, place of residence, education, marital status or income level. This was fully corroborated by the in-depth interviews held in summer 2014.

Monitoring data have revealed the dynamics of the respondents' opinions on whether there is a perceived danger of ethnic identity loss for Tatars. Between 2001 and 2010 the percentage of respondents who do not fear such loss has increased from $11,8 \%$ to $17,3 \%$.

The data obtained must be taken into account when developing the federal and regional ethnic policies in order to help revitalize ethnic identities and harmonize relations between representatives of various nationalities and religions.

Keywords: Siberian Tatars, Tyumen oblast, Islam, religious revival, Tatars, ethnic identity, religious identity. 


\section{REFERENCES}

Artiukhov, A. V. and Khairullina, N. G. (2012) Tendentsii etnokul'turnoi situatsii v severnom regione [The tendencies of ethno-cultural situation in the Russian North region]. Znanie. Ponimanie. Umenie, no. 3, pp. 106-109. (In Russ.).

Gavrilov, Yu. A. and Shevchenko, A. G. (2012) O nekotorykh tendentsiiakh izmeneniia etnoreligioznoi struktury naseleniia Rossii [Some trends in ethnic and religious structure of the Russian population]. Vestnik Instituta sotsiologii, no. 4, pp. 61-78. (In Russ.).

Dargyn-ool, Ch. K. (2003) Kul'tura kak osnova sotsial'nogo razvitiia regionov Rossii (na primere Tuvy) [Culture as a basis for social development of Russian regions (The case of Tuva)]. Gumanitarnye nauki v Sibiri, no. 3, pp. 40-43. (In Russ.).

Dargyn-ool, Ch. K. (2005) Regional'nyi aspekt sotsial'nykh protsessov v sovremennoi Rossii [The regional aspect of social processes in contemporary Russia]. Sotsial'no-gumanitarnye znaniia, no. 1, pp. 338-346. (In Russ.).

Doroshin, B. A. (2010) Osnovnye arkhetipy sotsial'noi elity v mifologicheskikh predstavleniiakh narodov Povolozh'ia [Major archetypes of the social elite in the mythological views of the peoples of the Volga region]. Vestnik Povolzhskoi akademii gosudarstvennoi sluzbby, no. 2 (23), pp. 209-217. (In Russ.).

Lamazhaa, Ch. K. (2011) Arhaizatsiia obshchestva v period sotsial'nykh transformatsii [The archaization of society in the period of social transformations]. Znanie. Ponimanie. Umenie, no. 3, pp. 35-42. (In Russ.).

Lamazhaa, Ch. K. and Khairullina, N. G. (2015) Arkhaizatsiia i neotraditsionalizm v regionakh Ural'skogo federal'nogo okruga [Archaization and neo-traditionalism in the regions of the Ural Federal District]. Znanie. Ponimanie. Umenie, no. 1, pp. 29-38. DOI: 10.17805/zpu.2015.1.3 (In Russ.).

Sibirskie tatary [Siberian Tatars] (2014) : A bibliographical reference book : (18 th century 2013) / comp. by A. Kh. Saifullina, G. N. Akhmetova and R. M. Nasibullin. Tyumen, Molot Publ. 449 p. (In Russ.).

Tatary $i$ islam $v$ regionakb Rossiiskoi Federatsii: religioznoe vozrozbdenie i etnichnost' [Tatars and Islam in the regions of the Russian Federation: religious revival and ethnicity] (2014) / ed. R. N. Musina. Kazan, Sh. Mardzhani Institute of History, Academy of Sciences of the Republic of Tatarstan ; Artifakt Publ. 348 p. (In Russ.).

Tatary Tiumenskoi oblasti: istoriia $i$ sovremennost' [Tatars of Tyumen oblast: past and present] (2011) / ed. by R. H. Nasyrov, N. G. Khairullina, V. S. Tashkalova and Z. A. Tychinskikh. Tyumen, Vektor Buk Publ. 310 p. (In Russ.).

Khairullina, N. G. (2010) Tatary Tiumenskoi oblasti: dinamika sotsiokul'turnoi situatsii [Tatars of Tyumen oblast: dynamics of the socio-cultural situation]. Tyumen, Tyumen State Oil and Gas University Publ. 208 p. (In Russ.).

Khairullina, N. G. (2011) Sotsiologicheskii aspekt iavleniia etnicheskoi identifikatsii tatar Tiumenskoi oblasti [The sociological aspect of the phenomenon of ethnic identification of Tatars living in Tyumen oblast]. Vestnik Orlovskogo gosudarstvennogo universiteta. Seriia: Novye gumanitarnye issledovaniia, no. 5 (19), pp. 69-72. (In Russ.).

Khairullina, N. G. (2012) Korennye narody Tiumenskoi oblasti: vzgliad sotsiologa [Indigenous peoples of Tyumen oblast: A sociologist's view]. Tyumen, Tyumen State Oil and Gas University Publ. 476 p. (In Russ.).

Khairullina, N. G. (2013) Mezhetnicheskie otnosheniia v polietnichnom rossiiskom regione: sotsiologicheskoe izmerenie [Inter-ethnic relations in a multiethnic Russian region: A sociological dimension]. Vestnik Kazanskogo gosudarstvennogo tekbnicheskogo universiteta im. A. N. Tupoleva, no. 1, pp. 182-184. (In Russ.).

Khairullina, N. G. (2014) Process religioznogo vozrozhdeniia i problemy etnicheskoi identichnosti $\mathrm{u}$ tatar Tiumenskoi oblasti [The process of religious revival and the issues of ethnic identity among the Tatars of Tyumen oblast]. In: Tatary $i$ islam $v$ regionakb Rossiiskoi Federatsii: religioznoe 
vozrozbdenie i etnichnost' [Tatars and Islam in the regions of the Russian Federation: religious revival and ethnicity]/ ed. R. N. Musina. Kazan, Sh. Mardzhani Institute of History, Academy of Sciences of the Republic of Tatarstan ; Artifakt Publ. 348 p. Pp. 277-307. (In Russ.).

Khairullina, N. G. and Koishe, K. K. (2013) Etnicheskaia identifikatsiia tatar Tiumenskoi oblasti: sotsiologicheskoe izmerenie [The ethnic identification of the Tatars of Tyumen oblast: A sociological measurement]. Znanie. Ponimanie. Umenie, no. 1, pp. 116-120. (In Russ.).

Khairullina, N. G. and Salikhova, A. R. (2004) Dinamika sotsiokul'turnoi situatsii na iuge Tiumenskoi oblasti [Dynamics of the sociocultural situation in the south of Tyumen oblast]. Tyumen, Tyumen State Oil and Gas University Publ. 128 p. (In Russ.).

Submission date: 12.02 .2015$.

Хайруллина Нурсафа Гафуровна - доктор социологических наук, профессор, профессор кафедры социологии Тюменского государственного нефтегазового университета. Адрес: 625000, Россия, г. Тюмень, ул. Володарского, д. 38. Тел.: +7 (3452) 45-35-26. Эл. адрес: nursafa@ inbox.ru

Khairullina Nursafa Gafurovna, Doctor of Sociology, Professor, Department of Sociology, Tyumen State Oil and Gas University. Postal address: 38 Volodarsky St., 625000 Tyumen, Russian Federation. Tel.: +7 (3452) 45-35-26. E-mail: nursafa@inbox.ru 